\title{
Management of a centenarian who underwent emergency laparoscopic cholecystectomy under general anesthesia with subcostal transversus abdominis plane block
}

Yoshiyuki Nagamine ${ }^{1}$, Kohei Godai ${ }^{1,2^{*}}$, Hiroshi Oki ${ }^{1}$ and Yuichi Kanmura ${ }^{2}$

\begin{abstract}
The anesthetic management of centenarians is challenging, since they have loss of functional reserve in all organs. The mortality rate of $25 \%$ is reported in patients over 100 years old who underwent emergency surgery. The transversus abdominis plane block has been shown to provide effective analgesia in laparoscopic cholecystectomy. A 101-year-old woman was diagnosed with grade I (mild) acute cholecystitis with gallstones. An emergency laparoscopic cholecystectomy was scheduled. The patient had a history of hypertension. The patient's laboratory data showed that she had mild coagulopathy, anemia, thrombocytopenia, and decreased renal function. After induction of general anesthesia, an ultrasound-guided, bilateral subcostal transversus abdominis plane block was performed. Her postoperative course was uneventful. Using the preoperative subcostal transversus abdominis plane block, we were able to avoid hemodynamic instability and to reduce opioid dosage in a centenarian who underwent emergency laparoscopic cholecystectomy under general anesthesia.
\end{abstract}

Keywords: Centenarian, Laparoscopic cholecystectomy, Transversus abdominis plane block

\section{Background}

The incidence of gallstones is known to increase with age [1]. Laparoscopic cholecystectomy (LC) is reported to be safe and feasible in patients older than 80 years [2]. The number of centenarians who undergo LC is, therefore, likely to continue increasing. The updated Tokyo Guidelines 2013 for acute cholangitis and acute cholecystitis recommend emergency LC for patients with grade I (mild) and grade II (moderate) acute cholecystitis [3]. Delayed elective cholecystectomy after gallbladder drainage should be performed in patients with grade III (severe) acute cholecystitis.

\footnotetext{
* Correspondence: kxg179@icloud.com

'Department of Anesthesiology, Kagoshima Prefectural Ohshima Hospital, 18-1 Nazemanadu, Amami, Kagoshima 894-0015, Japan

2Department of Anesthesiology and Critical Care Medicine, Graduate School of Medical and Dental Sciences, Kagoshima University, 8-35-1 Sakuragaoka, Kagoshima 890-8520, Japan
}

The anesthetic management of centenarians is challenging, since they have loss of functional reserve in all organs, decreased functional capacity, and imbalance of homeostasis. The mortality rate of $25 \%$ is reported in patients over 100 years old who underwent emergency surgery [4]. Although intraoperative and postoperative analgesia in patients undergoing LC can be achieved with intravenous opioid or thoracic epidural analgesia, there are concerns about opioid-related side effects and hemodynamic instability in the elderly patients [5]. The transversus abdominis plane block (TAPB) has been shown to provide effective analgesia in LC [6]. TAPB seems to be a preferable analgesia in the elderly patients undergoing LC. We here report an anesthetic management of a centenarian patient who underwent $\mathrm{LC}$ using TAPB.

\section{Case presentation}

A 101-year-old woman $(145 \mathrm{~cm}, 45.2 \mathrm{~kg})$ was diagnosed with grade I (mild) acute cholecystitis with gallstones. 
Although she had a 2-day history of right upper abdominal quadrant pain, Murphy's sign was not seen. She had a fever $\left(37.7{ }^{\circ} \mathrm{C}\right)$ and elevated C-reactive protein (24.3 $\mathrm{mg} / \mathrm{dl})$, white blood cell count $\left(15,520 / \mathrm{mm}^{3}\right)$, total bilirubin $(1.4 \mathrm{mg} / \mathrm{dl})$, and blood urea nitrogen $(28.2 \mathrm{mg} /$ dl). Gallbladder distention, pericholecystic fat stranding, and gallbladder wall thickening were seen on computed tomography. She did not show any signs of organ dysfunction or grade II (moderate) acute cholecystitis. Markedly elevated white blood cell count $(>18,000$ / $\mathrm{mm}^{3}$ ), palpable tender mass in the right upper abdominal quadrant, duration of complaints $>72 \mathrm{~h}$, and marked local inflammation (gangrenous cholecystitis, pericholecystic abscess, hepatic abscess, biliary peritonitis, emphysematous cholecystitis) are considered as signs of grade II (moderate) acute cholecystitis [7]. She was able to walk with a cane without help. She did not need any supports with eating, bathing, dressing, and toileting. An emergency LC was scheduled. Preoperative gallbladder drainage was not performed. Pre-anesthetic examination of the patient showed that she was taking telmisartan $30 \mathrm{mg}$ and losartan $50 \mathrm{mg}$ daily for hypertension. The patient's laboratory data showed that she had mild coagulopathy (prothrombin time international normalized ratio of 1.46 and activated partial thromboplastin time of $42 \mathrm{~s}$ ), anemia (hemoglobin concentration of $11.8 \mathrm{~g} / \mathrm{dl}$ ), thrombocytopenia (platelet count of $103,000 / \mu \mathrm{l}$ ), and decreased renal function (estimated glomerular filtration rate of $30.7 \mathrm{ml} / \mathrm{min} / 1.73 \mathrm{~m}^{2}$ ). We considered that the patient had an American Society of Anesthesiologists physical status of II. We planned general anesthesia with TAPB to avoid hemodynamic instability and to reduce opioid dosage.

General anesthesia was induced with midazolam $(3 \mathrm{mg})$ and fentanyl $(200 \mu \mathrm{g})$. Rocuronium $(30 \mathrm{mg})$ was administered to facilitate tracheal intubation. After induction of general anesthesia, we performed ultrasoundguided, bilateral subcostal TAPB. The patient had thin abdominal muscles. We injected $0.3 \%$ ropivacaine $25 \mathrm{ml}$ on each side (a total of $50 \mathrm{ml}$ ). General anesthesia was maintained with desflurane $3 \%$ and remifentanil $0.05-$ $0.15 \mu \mathrm{g} / \mathrm{kg} / \mathrm{min}$. Phenylephrine $5-12 \mu \mathrm{g} / \mathrm{min}$ was used to maintain mean blood pressure of $65 \mathrm{mmHg}$. A total of fentanyl $250 \mu \mathrm{g}$ was used during surgery. At the end of the procedure, $680 \mathrm{mg}$ of acetaminophen was given intravenously for postoperative analgesia. Residual neuromuscular block was antagonized with sugammadex $(2 \mathrm{mg} / \mathrm{kg})$ after confirming a train of four counts of two. After the extubation of the trachea, she had no pain at rest and on coughing (visual analogue scale of 0.0 and $0.0 \mathrm{~mm}$, at rest and on coughing, respectively). Loxoprofen $60 \mathrm{mg}$ was used for the first time postoperatively at $12 \mathrm{~h}$ after surgery. Oral intake was also resumed $12 \mathrm{~h}$ after surgery. Her postoperative course was uneventful.
The patient was discharged from the hospital on postoperative day 6 .

\section{Discussion}

This case report shows that TAPB provided adequate postoperative analgesia with sparing opioid dosage and avoiding hemodynamic instability in a centenarian patient who underwent LC.

$\mathrm{LC}$ is a safe procedure in the extremely elderly patients [2]. Four types of postoperative analgesia (intravenous opioid, thoracic epidural analgesia, TAPB, and port-site infiltration of local anesthetics) are mainly used in LC. Each of the four analgesia methods has its advantages and disadvantages. Intravenous opioid is the preferable choice in patients with severe coagulopathy or thrombocytopenia. Intravenous opioid, however, has catastrophic side effects like respiratory depression [8]. Since the elderly patients are prone to opioid-related side effects (respiratory depression, nausea, and sedation), anesthesiologists tend to avoid aggressive use of postoperative opioids [9]. Thoracic epidural analgesia is effective for both somatic pain and visceral pain. The major drawback of thoracic epidural analgesia is its sympathetic blockade effect which leads to hypotension and bradycardia. TAPB can be performed in patients with mild coagulopathy like our patient, since bleeding after TAPB is easy to stop with compression. Although TAPB is not effective for visceral pain, the authors considered that TAPB is the preferred analgesic choice for centenarian patients undergoing LC because of its analgesic effects and less side effects than intravenous opioid or thoracic epidural analgesia. There are several TAPB techniques, including lateral TAPB, subcostal TAPB, and posterior TAPB [10]. Port-site infiltration of local anesthetics is the easiest way of postoperative analgesia. Although lateral TAPB was reported to be equivalent to port-site infiltration of local anesthetics, subcostal TAPB provides superior postoperative analgesia and reduces opioid requirement following LC than port-site infiltration $[11,12]$. Compared with lateral TAPB, subcostal TAPB provides better postoperative analgesia [13]. In addition, preoperative subcostal TAPB may be able to reduce intraoperative opioids, and this is the reason why we selected preoperative subcostal TAPB.

The emergency surgery is known to be a risk factor for poor outcomes in elderly patients [14]. The mortality at postoperative 30 days among centenarian patients undergoing emergency surgery was reportedly $25 \%$ [4]. Since intraoperative hypotension is associated with a 30 day mortality, phenylephrine $5-12 \mu \mathrm{g} / \mathrm{min}$ was used in the patient to avoid hypotension [15]. The authors used a total of $150 \mathrm{mg}$ ropivacaine $(3.3 \mathrm{mg} / \mathrm{kg})$. The dosage is above the maximum recommended dose $(3 \mathrm{mg} / \mathrm{kg})$ [16] The patient did not show any signs of local anesthetic 
systemic toxicity. Loxoprofen was used in the patient despite her having decreased renal function. The use of NSAIDS in fragile elderly, often hypovolemic patients with limited renal functional reserve, is not recommended [17]. We should have chosen acetaminophen instead of non-steroidal anti-inflammatory drugs in the very elderly patients. The patient was successfully managed without any complications during the perioperative period.

\section{Conclusions}

In conclusion, we were able to avoid hemodynamic instability and to reduce opioid dosage in a centenarian who underwent emergency LC under general anesthesia with subcostal TAPB.

\section{Abbreviations}

LC: Laparoscopic cholecystectomy; TAPB: Transversus abdominis plane block

\section{Acknowledgements}

None.

\section{Authors' contributions}

KG provided the anesthetic care. YN and KG drafted the manuscript. $\mathrm{HO}$ and YK helped to draft the manuscript and revised it critically. All authors read and approved the final manuscript.

\section{Competing interests}

The authors declare that they have no competing interests.

\section{Consent for publication}

Written informed consent was obtained from the daughter of the patient for the publication of this case report and any accompanying images. A copy of the written consent is available for review by the Editor-in-Chief of this journal.

Received: 27 June 2016 Accepted: 13 September 2016

Published online: 23 September 2016

\section{References}

1. Shabanzadeh DM, Sorensen $L T$, Jorgensen T. Determinants for gallstone formation - a new data cohort study and a systematic review with metaanalysis. Scand J Gastroenterol. 2016;51:1239-48.

2. Lee SI, Na BG, Yoo YS, Mun SP, Choi NK. Clinical outcome for laparoscopic cholecystectomy in extremely elderly patients. Ann Surg Treat Res. 2015;88: 145-51.

3. Yamashita Y, Takada T, Strasberg SM, Pitt HA, Gouma DJ, Garden OJ, et al. TG13 surgical management of acute cholecystitis. J Hepatobiliary Pancreat Sci. 2013;20:89-96.

4. Konttinen $\mathrm{N}$, Rosenberg $\mathrm{PH}$. Outcome after anaesthesia and emergency surgery in patients over 100 years old. Acta Anaesthesiol Scand. 2006;50 283-9.

5. Nishikawa K, Kimura S, Shimodate Y, Igarashi M, Namiki A. A comparison of intravenous-based and epidural-based techniques for anesthesia and postoperative analgesia in elderly patients undergoing laparoscopic cholecystectomy. J Anesth. 2007;21:1-6.

6. Peng K, Ji FH, Liu HY, Wu SR. Ultrasound-guided transversus abdominis plane block for analgesia in laparoscopic cholecystectomy: a systematic review and meta-analysis. Med Princ Pract. 2016;25:237-46.

7. Yokoe M, Takada T, Strasberg SM, Solomkin JS, Mayumi T, Gomi H, et al. TG13 diagnostic criteria and severity grading of acute cholecystitis (with videos). J Hepatobiliary Pancreat Sci. 2013:20:35-46.

8. Overdyk F, Dahan A, Roozekrans M, van der Schrier R, Aarts L, Niesters M. Opioid-induced respiratory depression in the acute care setting: a compendium of case reports. Pain Manag. 2014;4:317-25.

9. Koh JC, Lee J, Kim SY, Choi S, Han DW. Postoperative pain and intravenous patient-controlled analgesia-related adverse effects in young and elderly patients: a retrospective analysis of 10,575 patients. Medicine (Baltimore). 2015;94:e2008.

10. Hebbard P. TAP block nomenclature. Anaesthesia. 2015;70:112-3.

11. Ortiz J, Suliburk JW, Wu K, Bailard NS, Mason C, Minard CG, et al. Bilateral transversus abdominis plane block does not decrease postoperative pain after laparoscopic cholecystectomy when compared with local anesthetic infiltration of trocar insertion sites. Reg Anesth Pain Med. 2012;37:188-92.

12. Tolchard S, Davies R, Martindale S. Efficacy of the subcostal transversus abdominis plane block in laparoscopic cholecystectomy: comparison with conventional port-site infiltration. J Anaesthesiol Clin Pharmacol. 2012;28: 339-43.

13. Bhatia N, Arora S, Jyotsna W, Kaur G. Comparison of posterior and subcostal approaches to ultrasound-guided transverse abdominis plane block for postoperative analgesia in laparoscopic cholecystectomy. J Clin Anesth. 2014:26:294-9.

14. McGillicuddy EA, Schuster KM, Davis KA, Longo WE. Factors predicting morbidity and mortality in emergency colorectal procedures in elderly patients. Arch Surg. 2009;144:1157-62

15. Mascha EJ, Yang D, Weiss S, Sessler DI. Intraoperative mean arterial pressure variability and 30-day mortality in patients having noncardiac surgery. Anesthesiology. 2015;123:79-91.

16. Williams DJ, Walker JD. A nomogram for calculating the maximum dose of local anaesthetic. Anaesthesia. 2014;69:847-53.

17. Sladen RN. Renal physiology. In: Miller RD, editor. Miller's anesthesia. 6th ed. Philadelphia: Elsevier, Churchill Livingstone; 2005. p. 803-25.

\section{Submit your manuscript to a SpringerOpen ${ }^{\circ}$ journal and benefit from:}

- Convenient online submission

- Rigorous peer review

- Immediate publication on acceptance

- Open access: articles freely available online

- High visibility within the field

- Retaining the copyright to your article

Submit your next manuscript at $>$ springeropen.com 